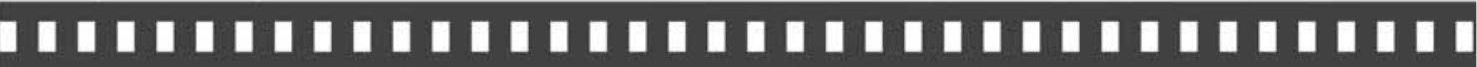

\section{Aylan Kurdi, Charlie Hebdo y el acontecimiento}

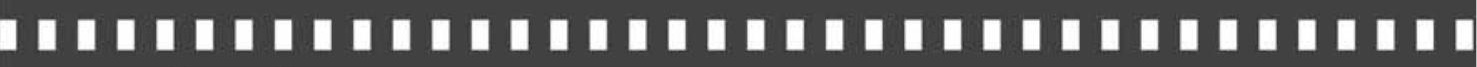

\author{
Sergio Roncallo-Dow \\ Diego Mazorra-Correa
}

Artigo recebido em: 10/09/2015

Artigo aprovado em: 11/12/2015 


\title{
Aylan Kurdi, Charlie Hebdo y el acontecimiento *
}

Aylan Kurdi, Charlie Hebdo and the event

\author{
Sergio Roncallo-Dow ** \\ Diego Mazorra-Correa *** \\ Lo cómico, para producir todo su efecto, exige una \\ anestesia momentánea del corazón. \\ H. Bergson. \\ Di te, finzione, mi cingo, fatua veste \\ Elsa Morante
}

\begin{abstract}
Resumen: En este artículo intentamos analizar la caricatura publicada por Charlie Hebdo en septiembre de 2015 a propósito de la fotografia de Aylan Kurdi yaciendo muerto en una playa turca. Introducimos la idea del acontecimiento mediático en dos órdenes y buscamos ubicar el lugar de la fotografía en el actual régimen de lo visible. Proponemos pensar la propuesta de Charlie Hebdo desde la idea clásica de la disfunción narcotizante.
\end{abstract}

Palavras clave: acontecimiento, fotografia, Charlie Hebdo, Aylan Kurdi, shitstorm.

\begin{abstract}
In this article we seek to analize the image published by Charlie Hebdo in September 2015 regarding the photograph of Aylan Kurdi lying dead on the shore of a beach in Turkey. We introduce the idea of the media event in two stages and we seek to place the photography on the current realm of the visible. We propose to look at the Charlie Hebdo image from the clssic idea of the narcotic disfunction.
\end{abstract}

Keywords: event; photography; Charlie Hebdo; Aylan Kurdi; Shitstorm.

* Este artículo fue desarrollado gracias al apoyo del Fondo Patrimonial para la Investigación de la Universidad de La Sabana en el proyecto (Com-62-2013): Cultural Transductions Universals and Lacunae: An international Contra-flow study

** Profesor de la Faculdad de Comunicación de la Universidad de La Sabana.

*** Profesor de la Faculdad de Comunicación de la Universidad Externado de Colombia. 


\section{Prefacio}

La foto de Aylan ha golpeado las retinas y conciencias del mundo. Nos ha sacudido, nos ha agitado, nos ha metido una sobredosis de realidad y hasta los más reticentes han reaccionado, al menos en un primer momento. Claro, Aylan era niño y estaba muerto. Los vivos no impresionan tanto, es más, pueden intranquilizarnos, llegar incluso a hacernos temer, a causarnos miedo. Pero tranquilos, de este impacto también nos recuperaremos. Ya lo hemos hecho más veces. Pronto, esa imagen, hoy viral, que nos ha conmovido a la conciencia del mundo próximo, real, cuyos habitantes se mueren en nuestras orillas, esa imagen que nos ha movido a la solidaridad, no siempre sólida, con esas miles de personas que huyen de la guerra o tan sólo buscan una vida mejor, acaso sólo seguir vivos; esa imagen viral, digo, debidamente tratada e interpretada -ya un diputado hijo de la Gran Bretaña, llamado Peter Bucklitsch, dijo que Aylan «murió porque sus padres fueron codiciosos con la vida europea»- bien sustituida por otras imágenes más recientes de los refugiados a los que hoy, tan tristemente, representa, será ya vacuna que nos inmunice nuevamente -la conciencia y sus humanas virtudes son cosas que, cual gripe, hay que inmunizar periódicamente- contra tanta sensiblería hacia el otro. Tiempo al tiempo y ojalá esté yo errando en mi apreciación (CAMPAL, 2015).

\section{Primer orden}

El 2 de septiembre de 2015 el mar arrojó a las playas de la costa turca a Aylan Kurdi, un niño sirio de tres años. La fotografía de su cadáver dio la vuelta al mundo: era el horror de la tragedia de los refugiados, la inocencia de un niño que moría tratando de alcanzar su libertad. Junto a Aylan murieron su hermano Galip, de 5 años y su 
madre, Rehan (y una docena más de sirios que buscaban, de manera desesperada, alcanzar las costas griegas). segregação racial.

La imagen de Aylan, fotografiada por la turca Nilüfer Demir, rápidamente dio la vuelta el mundo convirtiéndose en una imagen viral, en uno de esos acontecimientos que provocan una suerte de mirada sobre el otro, sobre aquel que es invisible hasta ser objetivado en la imagen fotográfica, en la producción del acontecimiento mediático mismo. Ya Deleuze nos recordaba que el acontecimiento funciona bajo la forma de un vector de modelación. Muchas veces nos enfrentamos a lo que podríamos llamar "ocurrencias". Los medios de comunicación sobrecargan nuestro entono perceptivo $\mathrm{y}$ nos llenas de múltiples estímulos a los cuales reaccionamos (en un sentido medianamente hipodérmico) de maneras más o menos activas. El hambre, la guerra, la muerte, se cosifican de forma tal que entran en el régimen cotidiano de circulación semiótica y provocan una suerte de anestésica colectiva (BUCK-MORSS, 2005) que induce un efecto de adormecimiento - una suerte de variación de la hoy clásica disfunción narcotizante (LAZARSFELD \& MERTON, 1948) - y una extraña sensación de actividad con la pura recepción del hecho mismo. En el caso de la propuesta de Deleuze,

los acontecimientos se distinguen en primer término porque su aparición se produce siempre por contraste con un ruido de fondo; en cada caso existe un telón caótico sobre el cual se esboza su silueta. Frente a la indiscernibilidad que caracteriza a las singularidades en el seno del caos, el acontecimiento introduce un orden, un principio de clasificación, una secuencia, un punto de referencia gracias al cual ingresamos en el universo del sentido (ORDÓÑEZ-DIAZ, 2011).

Dentro de la categoría del acontecimiento, la técnica permite un manejo de este: la fotografía. La fotografía es, en palabras de Sontag (recuperada por Butler (2007)), una emanación de un evento y se aleja de la representación. El evento, así seleccionado por un fotógrafo, no tendría otra interpretación más que la que le sea otorgada por un texto explicativo o por la lectura que haga el 
espectador. La fotografía, así vista, sería un templo sagrado del evento, puro y libre de interpretaciones añadidas por el espectador, y sólo sería interpretada en tanto se le añadiera un marco. Cuando el evento del que se habla es un evento traumático, como en las guerras, el evento transforma a los espectadores en testigos de eventos que se escapan incluso a la propia mortalidad (MÖLLER, 2010).

En un primer momento se piensa que las imágenes fotográficas de elementos violentos son rechazadas por los espectadores, así Carruthers (2008) explica cómo ante la guerra en Irak algunos ciudadanos prefirieron desviar la mirada, algo que Carruthers, retomando a Richards y Sheridan (1987, p . 405-6), ya se había notado con los británicos después de la Segunda Guerra Mundial cuando rechazaban películas de guerra, bombardeos y cuerpos lastimados. Pero las imágenes y su circulación en tiempos de guerra tiene otra mirada, al del uso político de las imágenes producidas en tiempos de guerra ${ }^{1}$. Esto, ya lo veremos, hoy tiene otros matices.

Para Butler (2007, p. 957) esto se explica, al contrario que la explicación de Sontag, en que si la fotografía es efectiva en informar o generar movilización política es gracias que es recibida en un contexto en el que se vuelve relevante para la conciencia política El evento seleccionado para la fotografía es enmarcado, como por ejemplo se hace con las fotografías relacionadas con acciones violentas y la memoria de esos hechos. Sugiere Berger (1991), cómo el uso de las fotografías nos remite al problema de la memoria,

Así, Gardner menciona: Un tercer tema de preocupación son los efectos socioeconómicos de las nuevas innovaciones en las tecnologías de información. En el aspecto social, los medios de comunicación (desde Marshall McLuhan y su "aldea global") ha tenido un impacto psicológico y social impresionante. Los efectos homogeneizantes de los medios de comunicación globalizados tienden a alienar a los grupos y liderazgos que subconscientemente (y conscientemente) absorben las imágenes, los valores y las concepciones presentadas por los nuevos medios. Por un lado, los nuevos sistemas de comunicación difunden nuevas ideas e imágenes que posiblemente pueden ayudar a las reformas, si no a las revoluciones pacíficas "progresistas". Por otra parte, también pueden trabajar para alienar las élites y grandes segmentos de la población, lo que puede causar una reacción violenta. Lo que cambia en la actualidad, especialmente desde el advenimiento de la computadora personal, el teléfono móvil e internet, es que la nueva revolución de las tecnologías de información ofrecen mayores oportunidades para los activistas alienados de intercomunicar, interactuar e intervenir unidos" (GARDNER, 2009 .Traducción de los autores). 
pero ligada la construcción de un contexto para la fotografía, algo, sean otros textos u otras fotografías que acompañen a la imagen. Aunque la fotografía muchas veces se usa como un solo documento de verdad (así fue), la memoria no es tan lineal, sino radial, con diversas asociaciones a un mismo evento, y no está en su tiempo original, de cuando fue tomada, sino en el tiempo narrado, así la fotografía es vista en términos simultáneos: personales, políticos, económicos, dramáticos, de la vida cotidiana e histórico. Para Marianne Hirsch (1999) esto se convierte en un problema cómo las imágenes fruto de la cámara fotográfica median las memorias públicas y privadas (en el Holocausto Nazi en este caso, pero la reflexión puede extenderse), generando memorias estéticas para las generaciones siguientes a quienes vivieron esta época.

Esto sucede en particular con las fotografías infantiles: cuando una persona que fue niña en la época observa su fotografía y triangula su recuerdo privado de su infancia con el contexto público que enmarca la época. Así se generan afiliaciones del sujeto a sus memorias, tanto como miembro de una generación como de partícipe de un momento histórico particular. La categoría utilizada por Hirsch es la de postmemoria, en la que la conexión de la fuente histórica con la memoria social no está mediada por la recolección sino por la proyección, inversión y recolección. Esta memoria además implica comprender, sobre todo en contextos traumáticos como el Holocausto, el dolor y sufrimiento de otros (que Hirsch denomina como "Heteropathic Memory", tomando la categoría prestada de Silverman (1996)), dependiendo solamente de la cercanía o la distancia cultural o coincidencia temporal. En estas fotografías se reafirma el pasado así como múltiples presentes (HIRSCH, 1999).

Existen dos memorias, una cultural y otra comunicativa (ASSMANN, 2008). La comunicativa es una memoria directa, transmitida por los testigos y por tanto de corta duración, mientras que la cultural es posterior, una postmemoria. Así, en eventos como el holocausto, la memoria de las fotografías pueden ser interpretadas 
por testigos, por las mismas personas que aparecen en las fotografías, y culturalmente, estas fotografías pasan a ser parte de nuevas generaciones a través de otros soportes propios de la memoria cultural como el cine. Así Auschwitz entra en la cultura, y el horror se vuelve estético (CHÉROUX, 2007). La poesía puede escribirse después de Auschwitz (¿después de Aylan?) ¿pero a qué costo? La fotografía, registro por excelencia de la memoria comunicativa y directa, que daba la impresión de la historia, pasa a ser parte de la memoria cultural, se produce como una obra de arte en algunos casos, se convierte en foro en otros (BUCHENHORST, 2007).

Una última consideración hasta aquí. Arfuch observa la relación del archivo y la memoria, no sólo en la narración testimonial que da forma, sino también en la idea del monumento ${ }^{2}$. Sólo que esta idea del monumento también se enfrenta a "lo irrepresentable del acontecimiento" que sería: "retorno a una actitud contemplativa premoderna: la memoria fotográfica o de los objetos actualiza ante nosotros el hábito ancestral de la adoración, el valor del ícono, el fetiche" (2008).El acontecimiento en la fotografía es así algo sagrado, pero existen dos momentos en los que este marco puede perder su valor, la reproducción y su eliminación del ámbito de lo sagrado.

\section{Re-pensar el acontecimiento}

Por supuesto, el punto a re-pensar aquí tiene que ver con el tipo de orden que introduciría lo que hemos llamado más arriba el acontecimiento mediático. Si aceptamos la idea, siguiendo a Deleuze de que se trata de vector de modelación, cabe pensar, entonces, en el tipo de modelación que se produce desde el ecosistema mediático y

2 Esta idea del "monumento" implicaría una reflexión mucho mayor. ¿Cómo hacer un monumento de lo que no se puede ver? ¿Cómo hacer un monumento de lo desaparecido? ¿Es el monumento una forma con ribetes religiosos? Sabemos la importancia de estas preguntes, pero escapan a la reflexión que aquí proponemos. 
las consecuencias que traen en términos de una modelación de la percepción de la realidad. La potencia performática de los acontecimientos mediáticos es, a todas luces, diversa. Su forma de actuar y producir efectos sobre lo real tiene - a esto apuntamos con la idea de potencia performática- , ante todo, una potencia determinada por la recepción; "la situación fenomenológica de la fotografía no es la experiencia del acto violento en sí mismo, sino que, al parecer, la experiencia del dolor cobra sentido en relación con los espacios en los cuales van a ser insertas las imágenes fotográfi $\neg$ cas" (OLAYA \& HERRERA, 2014): en la instauración yace la potencia performática del acontecimiento mediático. No es lo mismo pensar en la fotografía de Aylan tendido en la playa que en la miríada de imágenes fotográficas (que también imaginan la muerte) que a diario colonizan los periódicos a lo largo del mundo ¿Qué es lo que sucede allí?

Primero existe un cambio del acontecimiento en el momento de su reproducción en un ambiente de consumo de imágenes en internet. Primero, podemos decir con Butler que: "el fotógrafo está capturando el evento, pero cuando decimos que el fotógrafo está grabando el evento, implica pensar en la audiencia misma" (2007). Segundo, la circulación de la imagen de fotografías en internet genera otro encuadre, el del humor, la crítica política y la indignación. Shifman (2007), propone que en internet se puede presentar un campo de estudios desde la retórica antigua y el humor hasta los estudios de internet, dentro de la categoría Humor Hub en el que la relación entre humor y su contenido en los ambientes digitales de internet son globales gracias a que su principal forma de circulación es la visualidad (BUTLER, 2007). Biella Coleman trabaja sobre la misma línea, muchas de las agrupaciones de internet manejan el lenguaje del humor, al fin y al cabo, todo es una marcada hipérbola y un espectáculo entre trolls, hackers y expertos en bromas telefónicas - quizás no al estilo Bart Simpson, más bien como Kevin Mitnick (COLEMAN, 2012). El acontecimiento en internet pasa 
entonces por dos transformaciones: su reproductibilidad y su relación con el uso de muchas comunidades del humor como crítica $\mathrm{y}$ forma de mostrar su opinión en indignación.

Sobre este punto en particular, Byung-Chul Han (2014) ha reflexionado - quizás de manera un tanto apocalíptica- a partir del concepto de la shitstorm $^{3}$ y del problema de la indignación efímera en las redes sociales mostrando el modo en el que, a nuestro juicio, funcionaría el vector de modelación de los acontecimientos mediáticos. Dice Han:

El tejido digital favorece la comunicación simétrica. Hoy en día los participantes en la comunicación no consumen las informaciones de modo pasivo sin más, sino que ellos mismos las engendran de forma activa. Ninguna jerarquía inequívoca separa al emisor del receptor. Cada uno es emisor y receptor, consumidor y productor a la vez. Pero esa simetría es perjudicial al poder. La comunicación del poder transcurre en una sola dirección, a saber, desde arriba hacia abajo. El reflujo comunicativo destruye el orden del poder. La shitstorm es una especie de reflujo, con todos sus efectos destructivos .

Aquí, por supuesto, se evidencia una lectura que, en un primer nivel, sugiere la desconfianza respecto del ecosistema que instauran las redes sociales pero, a la vez, podrían entreverse consecuencias más interesantes. Los medios de comunicación no deben ser pensados simplemente desde la lógica del consumo de signos sino, más bien, como máquinas que producen conductas, que operan directamente sobre los modos de percepción y reacción ante lo real. Lo interesante de la propuesta de Han tiene que ver con la posibilidad de concebir los modos de modelación del acontecimiento mediático desde la lógica del poder (esto no es nuevo) pero pensados

Esta es una definición que ha circulado en internet y sus páginas de humor hace mucho tiempo. Aclara Raúl Gabás, traductor del texto de Han (2014): "Shitstorm significa, literalmente, "tormenta de mierda". Se usa en el sentido de tormenta de indignación en un medio de internet". En http://www.urbandictionary.com/ la noción tratada por Han se acerca a la quinta acepción de esa palabra que la define como "Una discusión acerca de algo sin sentido e inocuo que se sale de control y que consiste en una pelea acerca de nada”(MUDKIPS, 2007, traducción de los autores). 
desde la idea de lo efímero, implícita en la shitstorm. Esto es, si la idea de Deleuze sugería pensar el acontecimiento en términos de un ordo ab chao, la noción misma del acontecimiento mediático nos remitirá a una organización de lo real que pasa por la velocidad de la circulación de las imágenes y por un efecto que llamaremos sísmico (para evidenciar su carácter violento e inesperado) que se modela desde la recepción. Como lo recuerda Valdettaro:

La turística playa en la cual el mar escupió los cuerpos de varios niños, entre ellos el de Aylan Kurdi y el de su hermano Galip, de 5 años, devela la profunda impotencia de los organismos globales y coloca al turismo internacional en una contigüidad con el horror que parece, por momentos, no tener efectos. Sin embargo, la prensa global declara, con su habitual estridencia, que el niño muerto "despertó la ira de Occidente ante la tragedia del flujo migratorio" (ABC.es, 2015). El poder icónico-indicial de esa fotografía de un niño análogo a cualquier otro occidental, yaciendo en la arena, casi como durmiendo, produjo un instantáneo bucle de retroalimentación en la mediatización global, y la historia se desplegó plena de detalles: estaban navegando junto a otras 18 personas hacia Kos, una isla griega, en dos embarcaciones que habían partido de Akyarlar en la península de Bodrum, Siria (ABC.es, 2015) (2015).

Entra en juego aquí el problema del acontecimiento mediático y la modelación. Si bien la fotografía de Aylan tiene un efecto de bucle, una viralidad que genera una modelación de lo real en tanto supone una suerte alteración en la sensibilidad misma, compromete un cambio en el régimen estético del presente. Retomemos lo planteado por Roncallo y Arias (2013) para pensar la diferencia entre un acontecimiento y una simpe ocurrencia. "Ocurrencia" es lo que encuentra una representación posible, mientras que el acontecimiento es lo que irrumpe en la vida diaria y disloca los típicos mecanismos de entendimiento; Mitchell lo define como "el lugar donde las palabras y las imágenes fallan, donde son negadas, prohibidas como obscenidades que violan la ley del silencio y la invisibilidad, del mutismo y la ceguera" (2011). Es lo que no se 
puede decir, lo que está más allá de cualquier intento de la representación. El acontecimiento, diríamos, es capaz de crear mundos posibles (LAZZARATO, 2003). El efecto inmediato de este evento es sísmico. Su irrupción en vida cotidiana implica una imposibilidad inicial de comprensión. Eso es el razón principal para la multiplicación y la repetición de las imágenes. A través de ellas intentamos comprender lo que escapa a la compresión común de la realidad, lo in-imaginable. Como lo recalca Rubiano, "la simulación [en lo in-imaginable de la imagen fotográfica] sería la evidencia de la imposibilidad de hacer experiencia", el alejamiento narcótico-activo del acontecimiento mediático y su potencia modeladora.

La paradoja aquí, empero, nace desde otro lugar. La imagen de Aylan yaciendo sin vida en la playa está marcada por una suerte de aura que encuentra su cultualidad en la shitstorm de Han: indignación, viralización y la consecuente narcosis. El drama del refugiado, del que está a merced de la naturaleza y en los márgenes del discurso

despliega una narrativa en la cual se instala un espacio ambivalente; por una parte, para las propias masas migrantes, el componente de ofrenda de las imágenes del niño muerto se torna heroico y emblema identificatorio, confiriéndose, simultáneamente, una dimensión de sentido performático-publicitario en cuanto ícono global de las demandas de los contingentes de individuos segregados; por otra parte, para las ciudadanías occidentales bienpensantes, las cruentas imágenes de dicho componente segregado de las masas migrantes ocurre bajo la lógica de un don impensado (Mauss, 1971), que instala una cadena de deudas con la propia especie, manifestada, en ocasiones, como responsabilidad, $y$ en otras, directamente, como culpa (VALDETTARO, 2015).

La reflexión de Valdettaro incluye, a nuestro modo de ver, el componente clave de la shitstorm de Han: el de la narcosis activa. La culpa y la deuda se asumen desde la circulación de la imagen y desde ellas aparece el discurso de lo in-imaginable. La imagen es el 
acontecimiento mediático mismo, logra fracturar la realidad en tanto es ella misma quien la instaura. La instaura, justamente, desde la narcosis que suspende el acontecimiento mismo en un presente prologado cuya duración tiene aquella que marca la shitstorm, aquel en el que desaparecen las preguntas por las causas y las consecuencias: "La densificación de acontecimientos, informaciones e imágenes hace imposible la demora. El veloz encadenamiento de fragmentos no deja lugar a una demora contemplativa. Las imágenes, que pasan de manera fugaz por la retina, no logran captar una atención duradera. Propagan su atractivo visual y se desvanecen" (HAN, 2015). Empero, hay un punto adicional: la posibilidad de producir lo que podríamos llamar el acontecimiento mediático de segundo orden.

\section{¿Acontecimientos de segundo orden?}

En su edición 1208 de septiembre de 2015, el semanario francés Charlie Hebdo -hoy célebre sobre todo por los sucesos del 7 de enero- dedicó una de sus imágenes (dibujada por Laurent Sourisseau - Riss - ) a la figura de Aylan (Figura 1): 
Figura 1: Caricatura de Aylan Kurdi en Charlie Hebdo

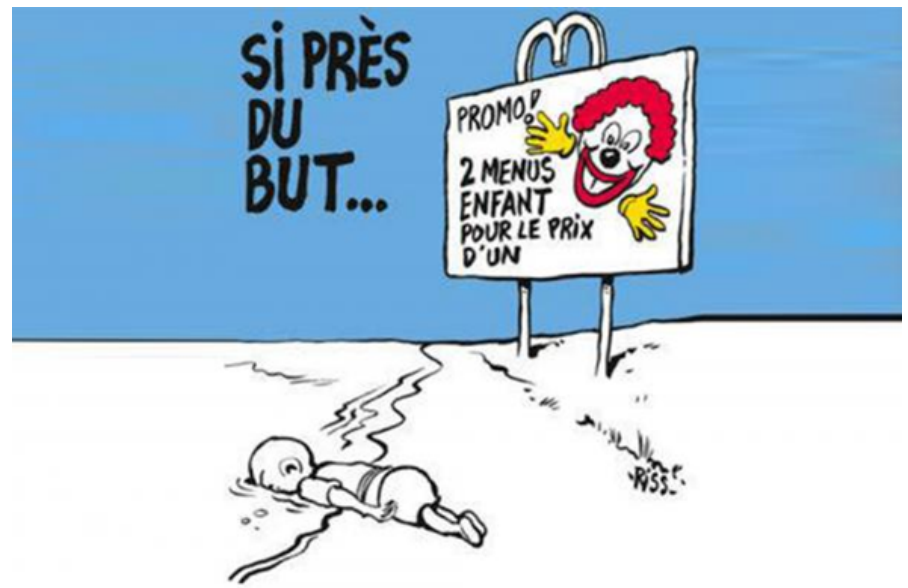

Fuente: Charlie Hebdo (No. 1208, 2015)

La pieza gráfica resultaba elocuente y, sobre todo, sísmica. La re-producción de un niño que yacía junto al mar, este nuevo Aylan Kurdi (la imagen-cuerpo-acontecimiento), era observada por Ronald McDonald, la misma figura que sugería la llegada de la democracia y la libertad a Moscú - a una esquina de la Plaza Roja- en 1990. "Tan cerca de la meta" (del objetivo) rezaba el texto principal: la meta para el marginal, la meta para ese invisible que (junto a una docena de turcos) buscaba llegar a las costas de Grecia. Desde lo alto de una valla el payaso anunciaba la fatalidad de la promesa incumplida: dos menús infantiles (cajitas felices, como se les llama en algunos países) por el precio de una; Aylan ya no podría probar el sabor de la libertad.

Sin duda, la pieza encaja perfectamente dentro de los modos de re-presentación de lo real de Charlie Hebdo, el semanario que se autodefine como "irresponsable" y que fue, él mismo, un acontecimiento mediático después del atentado de enero de este año. Lo interesante aquí tiene que ver con la idea del tipo de 
acontecimiento que produce la imagen que se genera a partir otra imagen. En los órdenes más tradicionales de lo visible la imagen es siempre imagen de algo y funciona a partir de una suerte de anclaje con lo real mismo. La fotografía de Aylan Kurdi en la playa remitía a la idea del fracaso de un proyecto cosmopolita (aquel que Kant (2003) imaginara alguna vez), a la idea de una infancia interrumpida, a la abyección misma de la condición del refugiado. La fotografía de Aylan era entonces un significante aglutinador mediado por la codificación colectiva y sólida producida por la narcosis activa del acontecimiento mediático: infante muerto, fracaso y abyección funcionan aquí bajo la forma del anclaje de la imagen. El acontecimiento que se desprende de ella produce, a su vez, un acontecimiento nuevo (de segundo orden), cuyo anclaje está dado por los efectos performáticos del acontecimiento de base y que instaura a su vez vectores de modelación de lo real.

La caricatura ${ }^{4}$ de-forma lo real en tanto lo violenta, lo carga, lo llena de otro sentido: eso es lo que sugiere el 'caricare' (en italiano, cargar, exagerar) que resuena en la palabra misma. La violencia - la carga- puede pensarse bajo la forma de la producción en el sentido del develamiento. Hay violencia cuando algo es des-velado y traído a la presencia, de algún modo, hay ruptura, hay una re-construcción de lo real: un des-ocultamiento que hace visible lo oculto, que hace imagen lo in-imaginable. En esto la imagen fotográfica y la caricatura encontrarían un punto en común. La imagen de Charlie Hebdo sigue un rumbo inverso. La página de Charlie Hebdo imagina lo ya imaginado y, en consecuencia, distorsiona el ejercicio del traer a la presencia. La re-imaginación de lo ya imaginado bajo la forma de la caricatura no supone aquí efecto alguno de comicidad ¿Por qué? Recordemos, por un momento a Bergson: "Entonces comprendemos lo cómico de la caricatura. Por regular que sea una

Puede objetarse aquí que la idea misma de 'caricatura' se refiere más a la de-formación de una persona en particular. Usamos esta palabra en lugar de 'viñeta' para evidenciar el hecho de que Riss provoca una remisión a un sujeto colectivo. La imagen que nos da Charlie Hebdo caricaturiza un universo semántico que puede ser subjetivizado. 
fisonomía, por armoniosas que supongamos sus líneas y por flexibles que nos parezcan sus movimientos, nunca se encuentra en perfecto equilibrio" (BERGSON, 1985). El problema aquí yace justamente en el equilibro. La caricatura no imagina nada, es imagen de la imagen que pretende caricaturizar pero mantiene sus puntos de anclaje intactos: la realidad no es violentada por la imagen de Riss. Nos lo recuerda Bergson con una experiencia cotidiana:

Una persona va apurada por la calle, tropieza y cae sentada en el suelo. Existen posibilidades de que esta situación sea cómica, pero si esta persona se hubiera sentado por decisión propia seguramente el efecto cómico no se produciría. Lo que está sucediendo es que la persona fue sorpresivamente sacada del contexto habitual de sus costumbres. De pronto, su movimiento habitualmente mecánico se vio modificado contra su voluntad. La risa castiga las costumbres (BERGSON, 1985).

Riss no produce risa. No hay comicidad en la medida en que se mantiene la relación de equilibro con el acontecimiento de primer orden y, en consecuencia, el acontecimiento mediático segundo genera una shitstorm igualmente narcótica cuyo punto de anclaje yace en lo in-imaginable precedente.

En este punto estriba, justamente, la elevación a segundo orden de la caricatura en tanto acontecimiento mediático. Es un acontecimiento tiene lugar sobre uno precedente $\mathrm{y}$, en tanto tal, genera efectos performáticos que desplazan el sujeto/causa de la shitstorm pero que mantienen intactos los fulcros de la narcosis colectiva. En palabras de Delia Rodríguez, "empezamos a bailar en un concierto cuando empiezan a moverse los que nos rodean, nos unimos a Facebook cuando lo hacen nuestros amigos, [y esto] no nos gusta que nos lo recuerden" (2013). Este es el punto: la imagen fotográfica y la caricatura movilizaron la narcosis desde el mismo lugar pero el acontecimiento de segundo orden aparecía como anclado a los efectos de la histeria colectiva anterior. La caricatura no es entonces la suspensión de lo real y su de-formación sino, más bien, la manera de des-imaginar lo in-imaginable en tanto su 
condición tiene las características propias de una doble efervescencia mediática: lo in-imaginable regresa al terreno de la ocurrencia y deja de escapar a la representación. El humor implícito en la idea misma de la caricatura desaparece para dar lugar a una especie de mohín colectivo que ya no conoce más que la duración de ese baile conductista - si se nos permite el término- que mencionábamos más arriba.

Ese es el encuadre de la fotografía en la caricatura, no es una parodia, es un marco de interpretación. Para Agamben (2007) esta caricatura no sería una parodia, la parodia es una relación que se rompe entre el lenguaje y el mundo, y en ese espacio se introduce el mundo de la ficción, un mundo que es literatura y está marcado por una narración sagrada. En otro estatuto de la parodia se encontraría la profanación. En la profanación lo que es sagrado, de los dioses, es en un sentido de la palabra sacrificado, devuelto al mundo mortal; así, lo sagrado pasa por una operación política para devolverlo a los hombres, y hombres sagrados (homo sacer en Agamben) son separados de la comunidad y pueden ser matados sin impunidad en el sacrificio a los dioses, que eso en sí una propia profanación.

Sugiere Agamben, siguiendo a Benjamin, el mundo capitalista ha creado una división que neutraliza la separación de lo sagrado y lo profano, en el mundo del consumo esta separación ya no importa. En el mundo del espectáculo (la otra cara del consumo) la separación de valor de uso y valor de cambio del marxismo tradicional introduce un nuevo elemento: el valor de su exhibición. Por ejemplo, el espacio de la pornografía, que vale por su exhibición, lo hace ya improfanable, pero la caricatura vale aún por sus palabras de enmarcan.

Permítasenos un breve rodeo para explicar una paradoja más, la paradoja política. El debate de la fotografía contra la caricatura ha sido una polémica tan desfasada como el que originó hace algún tiempo las caricaturas de Mahoma en Europa, entre libertad de expresión y sensibilidad religiosa, que escondía siglos de 
desencuentros culturales y de discriminación de occidente hacia las formas de hablar de oriente (HUSSAIN, 2007). En el encuadre político de la fotografía también operaba el encuadre de la shitstorm, que se originaba desde un impulso de Nilüfer Demir, la fotógrafa: "Aylan Kurdi, de tres años, yacía sin vida entre la espuma, con su camiseta roja y su pantalón azul oscuro pegado a la cintura. Todo lo que podía era hacer que se oyera su grito ${ }^{5}$ " (HURREYDAILYNEWS.COM, 2015, septiembre 3). Este impulso trae a la mente la idea de dar voz a aquel que no la tiene. El impulso de Demir podría traducirse, en primera instancia como la posibilidad de pensar en el otorgar voz a aquel que no la tiene, una idea particularmente rancieriana. En efecto, Aylan es un infante que, en su acepción latina -infantis- significa "el que no habla" o, en este caso, el que no tiene palabras - el que no tiene discurso-. Anclado al impulso fotográfico de Demir parecería yacer la cuestión política de dar voz a los que no tienen voz, el "hacer que se oyera su grito" se traduce en la proyección de un discurso que encarnaría Aylan pero que, en últimas, sería la voz de los refugiados de los que, en la geopolítica del presente continuo, no tienen parte. Esto es claro desde Rancière:

Hay política porque quienes no tienen derecho a ser contados como seres parlantes se hacen contar entre éstos e instituyen una comunidad por el hecho de poner en común la distorsión, que no es otra cosa que el enfrentamiento mismo, la contradicción de dos mundos alojados en uno solo; el mundo en que son y aquel en que no son, el mundo donde hay algo entre ellos y quienes no los conocen como seres parlantes y contabilizables y el mundo donde no hay nada (1996).

La paradoja de Aylan yace justamente allí. Su discurso y su ontología le son otorgados desde el acontecimiento mediático (en sus dos órdenes). Si Demir le otorga voz, esa posibilidad de devenir discurso pierde, justamente, su potencia en la medida en que deviene pura viralidad: en su condición de hashtag, \#Aylan es un sujeto-otro

Traducción de los autores. 
que es cosificado desde el discurso que su grito pretende aplacar. La imagen de Demir entra en el espacio "sin dirección" (HAN, 2015) de la red y allí el grito se ahoga en medio de muchas voces más que intentan ser oídas. Lo in-imaginable imaginado por la fotografía recobra forma de la representación - de la ocurrencia simple- en tanto deviene lo real mismo en un presente que no conoce causas ni consecuencias.

La caricatura de Riss eleva este punto a otro nivel. En tanto acontecimiento que se erige sobre uno precedente, el efecto de des-politización se traduce en una suerte de doble subalternización de lo subalterno mismo. Como lo ha mostrado Spivak (1994), el subalterno es aquel cuya voz se ve truncada entre el hablante y el oyente, aquel cuyo grito es emanado mas nunca oído: el subalterno no tiene potencia performática alguna, su grito se disuelve en el más puro de los silencios. Riss duplica el silencio al des-imaginar el acontecimiento: su caricatura devuelve el grito al lugar del silencio... Es más, quien habla es aquí Ronald McDonald, un payaso cuya sonrisa y su promesa del alimento feliz, del happy meal, hunde bajo el océano al niño sirio que yace a su lado.

Esta imagen del payaso que habla al cadáver es la misma que se entrevé en la publicidad de McDonald's (Figura 2): El doble de felicidad (esa que no se alcanzó a saborear "tan cerca de la meta") y la posibilidad de ayudar a un niño necesitado. 
Figura 2: publicidad de McDonald's

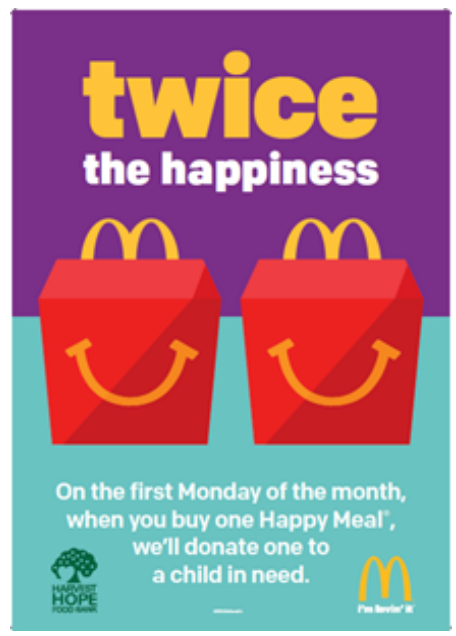

Fuente: (LEXINGTONMOMMY.COM, 2015)

La subalternización de Aylan pasa por esta lógica, la misma de la que hablara Slavoj Žižek (2009) cuando reflexionaba sobre Starbucks y la lógica del consumo adecuado. Lo que es clave aquí es pensar el recorrido que va desde la fotografía de Demir hasta la publicidad misma de McDonald's y el lazo que hay entre ellas: la imagen de Riss que funciona como una síntesis entre las dos. La desgracia del niño muerto arrojado por el mar y la promesa de la felicidad dentro de una caja de hamburguesa. Empero, volvemos aquí al lugar que sostiene nuestra reflexión: la carencia misma presente en Charlie Hebdo en tanto un ocultamiento del sentido político mismo, un silencio que silencia a los que no tienen voz. De ahí que los acontecimientos mediáticos no generen pregunta alguna $\mathrm{y}$ mantengan la narcosis colectiva. La producción del acontecimiento, lo sabemos ya, hace emerger mundos posibles pero, en este caso, la ontología que se le otorga previamente a Aylan desde el acontecimiento mediático (en sus dos órdenes) reitera el orden mismo de lo hegemónico, en palabras de Rancière (2000), de una 
cierta partición de lo sensible en la que se mantiene el orden previamente gestionado. En el fondo, este es el problema con Demir y con Riss: la ontologización de un subalterno al que se le otorga una función en el orden de lo sensible. Cuando a Aylan se le pone como tarea ser el grito de todos los refugiados -un poco al estilo de la voz de Auguste Blanqui hablando por los proletarios franceses en 1832 (RANCIÈRE, 1996)- se le otorga una función que lo deja igualmente sin voz, en tanto responde a una operación simbólica que se da desde el afuera, desde la lejanía, desde una lógica ya establecida. Después de todo, la cercanía y la lejanía son aquellas que alimentan hoy los compromisos éticos. Con situaciones lejanas hay un nivel bajo de compromisos, en el mejor de los casos se muestra solidaridad (con el hambre en el África, los desplazados por la violencia en Colombia, la causa de los Kurdos, Aylan y los refugiados - todos sustancializados bajo la idea de un único sujeto-). Ante este tipo de hechos se procede por medio de esas declaraciones indoloras sobre las que se fundamenta la ética que ha descrito Lipovetsky (1994). Esas son las declaraciones indoloras de lo políticamente correcto, las que alimentan la shitstorm y las que, a la postre, des-politizan y restan posibilidad performática a la imagen. La lejanía de la fotografía no permite la producción del acontecimiento pero hablar de ella en un presente continuo da la sensación de participación.

De igual modo, la shitstorm que se produce en el acontecimiento de segundo orden opera desde la tiranía de lo políticamente correcto. Si bien Riss intenta la operación contraria con la caricatura - lo irresponsable (marca semántica explícita de Charlie Hebdo), lo incorrecto- no produce risa porque no hay violencia, no hay deformación, no hay una irrupción sísmica en el sentido ya establecido. Riss devuelve a Aylan Kurdi al orden de la representación que, recuerda Lazzarato, es un orden en el que "las imágenes, los signos y los enunciados tienen como función representar el objeto, el mundo" (2003). La reiteración de la 
ocurrencia en el orden de la representación provoca el acontecimiento mediático de segundo orden que termina disolviéndose en una tormenta de trinos que devienen en la pura indignación del "niño ahogado". La intención original de Demir se disuelve en su contrario y terminamos asistiendo a la idea de una especie de consumo mediático responsable - similar al de aquel que compra productos orgánicos o, por supuesto, siguiendo la causa que todos consideran es la correcta-. El discurso que podría tener efectos políticos constatables, la re-partición del orden de lo sensible- se pierde en medio de una suerte de activismo cool (HEATH \& POTTER, 2005) en el que lo que prima es mostrar la propia indignación frente al acontecimiento mediático que, en ambos órdenes, se presenta como despolitizado. Hay aquí una extraña variación del conductismo propio de la Teoría Hipodérmica (WRIGHT, 1986) y el narcisismo hedonista que hace más de treinta años dibujara Lipovetsky (1986) ${ }^{6}$. Aunque aparentemente irreconciliables, estas dos versiones parecen encontrarse en medio de la shitstorm contemporánea: al estímulo colectivo propio del acontecimiento mediático (presente, plano, incuestionable) le sigue una respuesta homogénea pero, a la vez, hedonista y personalizada. Desde la indignación por lo incuestionable, Aylan se convierte en un icono que refuerza el impulso narcisista de la indignación. Como lo ha explicado Lipovetsky, la imagen llamada a ilustrar al sujeto posmoderno (ese que fue descrito has más de tres décadas) es, la de Narciso $^{7}$. La personalización supone un repliegue desde lo público hacia lo privado, sin embargo, sería erróneo ver en el Narciso que se propone aquí un individuo totalmente desconectado de la colectividad; se trata más bien de una indiferencia relajada, que

Nos referimos a la fecha de publicación en francés de L'Ère du vide : essais sur l'individualisme contemporain. La primera edición en castellano es la que referenciamos en nuestra bibliografía. Baste recordar aquí brevemente la historia de Narciso: hermoso hijo de la ninfa Liríope, encontró su desgracia al no poder soportar su belleza viendo su imagen reflejada en un estanque. Algunas variantes de la historia dicen que murió allí mismo, agobiado con la simple contemplación; otras sostienen que se ahogó al abalanzarse sobre las aguas buscando abrazar su propia imagen. 
libera lo público de su carácter cultual para dar paso a un individualismo que, por supuesto, privilegia el carácter de la vida privada. Lo que se da es un cambio en la noción misma de individuo, que apunta cada vez más a la particularización de los intereses y a un paulatino subsumirse del discurso público bajo el privado desde la narcosis colectiva. Al fin y al cabo, como lo recuerda Lipovetsky (1986), la sociedad posmoderna (de la que este individuo-narciso es parte fundante) carece de ídolos o tabúes, está regida simplemente por el vacío que no parece ser otra cosa que las nuevas formas de vida e interacción, propias de una época despreocupada por sus mitos fundacionales: una era en la que la producción y la revolución han sido reemplazadas por la inmediatez de la información y la "libre" expresión. Estímulo, respuesta y satisfacción hedonista: he ahí el fulcro de la des-politización.

\section{Bibliografia}

AGAMBEN, Giorgio. Profanations. New York: Zone Books, 2007.

ARFUCH, Leonor. Crítica cultural: entre política y poética. Buenos Aires: Fondo de Cultura Económica, 2008.

ASSMANN, Jan. Religión y memoria cultural. Buenos Aires: Ediciones Limold, Libors de la Araucaria, 2008.

BERGER, John. About Looking. New York: Vintage International (Random House), 1991.

BERGSON, Henri. La risa. Madrid: Sharpe, 1985. 
BUCHENHORST, Ralph. Testigos, científicos, artistas: ¿Cómo crear un foro de la memoria del terror? In: LORENZANO, Sandra e BUCHENHORST, Ralph. (Ed.). Políticas de la memoria: tensiones en la palabra y la imagen. Buenos Aires: Universidad del Claustro de Sor Juana, Editorial Gorla, 2007. p.231-246.

BUCK-MORSS, Susan. Estética y anestésica: una reconsideración del ensayo sobre la obra de arte. In: (Ed.). Walter Benjamin, escritor revolucionario. Buenos Aires: Interzona, 2005.

BUTLER, Judith. Torture and ethics of photography. Evironment and Planning D: Society and Space, v. 25, p. 951-966, 2007.

CAMPAL, Juanmaría. Mis nombres para Aylan. España.

Disponível em: <

http://www.lanuevacronica.com/mis-nombres-para-aylan $>$. Acesso em: 30 septiembre, 2015.

CARRUTHERS, Susan. No one's looking: the disappearing audience for war. Media, War \& Conflict, v. 1, n. 1, p. 70-76, 2008.

CHÉROUX, Clément. ¿Por qué sería falso afirmar que después de Auschwitz no es posible escribir poemas? In: LORENZANO, Sandra e BUCHENHORST, Ralph. (Ed.). Políticas de la memoria: tensiones en la palabra y la imagen. Buenos Aires: Universidad del Calustro de Sor Juana, Editorial Gorla, 2007. p.219-230.

COLEMAN, Gabriella. Freaks, Hackers, and Trolls: The Politics of Transgression and Spectacle. In: MANDIBERG, Michael. (Ed.).

The Social Media Reader. New York: New York University Press, 2012. p.96-119. 
GARDNER, Hall. War and the Media Paradox. In: KARATZOGIANNI, Athina. (Ed.). Cyber Conflict and Global Politics. New York: Routledge, 2009. p.13-30.

HAN, Byung-Chul. En el enjambre. Barcelona: Herder, 2014.

. El aroma del tiempo. Un ensayo filosófico sobre el arte de demorarse. Barcelona: Herder, 2015.

HEATH, Joseph; POTTER, Andrew. Rebelarse vende. EI negocio de la contracultura. Bogotá: Taurus, 2005.

HIRSCH, Marianne. Projected Memory: Holocaust Photographs in Personal and Public Fantasy. In: BAL, Mieke; CREWE, Jonathan, et al (Ed.). Acts of Memory. Cultural Recall in the Present. Hanover \& London: Dartmouth College, University Press of New England, v.2-23, 1999.

HURREYDAILYNEWS.COM. Photographer of the world-shaking picture of drowned Syrian toddler: 'I was petrified at that moment'. 2015, septiembre 3. Disponível em: <

http://www.hurriyetdailynews.com/photographer-of-the-world-shak ing-picture-of-drowned-syrian-toddler-i-was-petrified-at-that-mome nt.aspx?page $\mathrm{ID}=238 \&$ nid $=87951 \& \mathrm{News} C \mathrm{atID}=341>$. Acesso em: 30 septiembre, 2015.

HUSSAIN, Ali. The Media's Role in a Clash of Misconceptions: The Case of the Danish Muhammad Cartoons. Press/Politics, v. 12, n. 4, p. 112-130, 2007.

KANT, Immanuel. Sobre la paz perpetua. Madrid: Tecnos, 2003. 
LAZARSFELD, Paul; MERTON, Robert. Comunicación de masas, gustos populares y acción social organizada. In: DE MORAGAS, Miquel. (Ed.). Sociología de la comunicación de masas. Volumen II, Estructura, funciones y efectos. Barcelona: Gustavo Gili, 1948. p.22-49.

LAZZARATO, Maurizio. Lucha, acontecimiento, media. 2003. Disponível em: < http://eipcp.net/transversal/1003/lazzarato/es >. Acesso em: 30 septiembre, 2015.

LEXINGTONMOMMY.COM. McDonald's Buy One, Give One Happy Meals. 2015. Disponível em: < http://lexingtonmommy.com/blog/2015/05/04/mcdonalds-buy-onegive-one-happy-meals/ > . Acesso em: 25 septiembre, 2015.

LIPOVETSKY, Gilles. La era del vacío. Ensayos sobre el individualismo contemporáneo. Barcelona: Anagramas, 1986.

. El crepúsculo del deber: la ética indolora de los nuevos tiempos democráticos. Barcelona: Anagramas, 1994.

MITCHELL, William John Thomas. Cloning Terror: The War of Images, 9/11 to the Present. Chicago: University of Chicago Press, 2011.

MÖLLER, Frank. Rwanda Revisualized: Genocide, Photography, and the Era of the Witness. Alternatives: Golbal, Local, Political, v. 35, p. 113-136, 2010.

MUDKIPS. Shitstorm. 2007. Disponível em: < http://www.urbandictionary.com/define.php?term=shitstorm $>$. Acesso em: 25 septiembre, 2015. 
OLAYA, Vladimir; HERRERA, Martha Cecilia. Fotografía y violencia: la memoria actuante de las imágenes. Cuadernos de Musica, Artes Visuales y Artes Escenicas, v. 9, n. 2, p. 89-106, 2014.

ORDÓÑEZ-DIAZ, Leonardo. Arte y conocimiento. Una aproxiamción a la estética deleuziana. Revista Latinoamericana de Filosofía, v. XXXVII, n. 1, p. 127 - 152, 2011.

RANCIÈRE, Jacques. El desacuerdo. Política y filosofía. Buenos Aires: Nueva Visión, 1996.

. Le Partage du sensible : Esthétique et politique. Paris: La fabrique editions, 2000.

RODRÍGUEZ, Delia. Memecracia. Los virales que nos gobiernan. Barcelona: Gestión 2000, 2013.

RONCALLO, Sergio; ARIAS, Juan Carlos. Images of the unimaginable: Photography and the (re)presentation of the event. Discursos Fotograficos, v. 9, n. 14, p. 141-172, 2013. Disponível em: $<$

http://www.scopus.com/inward/record.url?eid=2-s2.0-8487712120 $6 \&$ partnerID $=40 \&$ md5 $=0731 \mathrm{~d} 3 \mathrm{e} 39 \mathrm{c} 83553 \mathrm{~d} 74 \mathrm{e} 283 \mathrm{a} 3 \mathrm{db} 662685>$. Acesso em: 25 septiembre, 2015.

RUBIANO, Elkin. La experiencia sustituida: hacia la construcción tecnológica de la nsotalgia. Palabra Clave, v. 16, n. 2, p. 541-558, 2013. 
SHIFMAN, Limor. Humor in the Age of Digital Reproduction:

Continuity and Change in Internet-Based Comic Texts.

International Journal of Communication, v. 1, p. 187-290, 2007.

SILVERMAN, Kaja. The Threshold of the Visible World. Great Britain: Routledge, 1996.

SPIVAK, Gayatri Chakravorty. Can the subaltern speak? Colonial Discourse and Post-Colonial Theory, p. 66-111, 1994.

VALDETTARO, Sandra. Mediatización: hacia una ecología performática de los restos y la deriva. Palabra Clave, v. 18, n. 4, p. 1128-1154, 2015.

WRIGHT, Charles. Mass Communication: A Sociological

Perspective. New York: Mcgraw-Hill, 1986.

ŽIŽEK, Slavoj. First as Tragedy, then as Farce. 2009.

Disponível em: <

https://www.thersa.org/discover/videos/event-videos/2009/11/firstas-tragedy-then-as-farce/ >. Acesso em: 3 septiembre, 2015. 